\title{
The Study on Construction Technique about The Reinforced Concrete Retaining Wall's Lateral Displacement Repairing
}

\author{
HAN Shang Yu ${ }^{1,2}$, LI Kai Ren ${ }^{2, a}$, Qiu Fang ${ }^{1}$ \\ ${ }^{1}$ Nanchang construction engineering group co. LTD, Nanchang City, Jiangxi Province, 330008; \\ 2 Nanchang Hangkong University, Nanchang City, Jiangxi Province, 330063)
}

\begin{abstract}
Based on the stress characteristics and the composition of lateral deformation about retaining wall structure, a kind of lateral displacement repairing construction technique of reinforced concrete retaining wall is proposed. Meanwhile, the process principle, construction process and quality control points of the technique are systematically analyzed in this paper. From the application effect of site engineering, the construction proposed in the paper has good engineering benefit and promotion value.
\end{abstract}

\section{Introduction}

Retaining wall is a common form of retaining structure in kinds of engineering construction, and it has been widely used in highway, railway, port engineering, construction engineering and other fields. In the course of use, because of the soil pressure, water pressure and other factors, the retaining wall will appear the lateral movement, lateral slip or overturning deformation, which mainly occurs between adjacent deformation joints, showing obvious fault in the position of deformation joint. It will lead to the deterioration of the force character and safety condition of the retaining wall occurs. If it is not disposed in time, it will seriously affect the stability, safety of retaining wall and the instability of retaining wall.

At present, scholars have carried out some researches on the retaining wall of construction measures, the water pressure and the soil pressure theory. For example, Paik et $\mathrm{al}^{[1]}$ established the active earth pressure calculation method by considering the soil arch effect in the translational mode. FANG et $\mathrm{al}^{[2]}$ proved that the displacement mode of the rigid retaining wall will have a significant influence on the distribution of soil pressure and the height of the result-joint operation point. $\mathrm{He}$ Shan Guo et $\mathrm{al}^{[3]}$ analyzed the forms and causes of the retaining wall's instability, and discussed the measures of the retaining wall's reinforcement about the disease, the old gravity type and the weight. Zhou Jian et $\mathrm{al}^{[4]}$ studied the distribution law of soil and water pressure after the wall by conducting model test and numerical simulation. Wei Xing Xing ${ }^{[5]}$ designed a structure to repair the retaining wall's lateral displacement in allusion to the influence factors. Based on the actual operation of the highway, Sun Jia Wen et al ${ }^{[6]}$ explored the reinforcement mechanism and stability improvement method of retaining wall. Li Zhen et a ${ }^{[7-10]}$ proposed the corresponding construction repair measures by analyzing the case of retaining wall reinforcement.

The analysis shows that the existing research results have positive significance for improving the lateral displacement repairing technology of the retaining wall, and some engineering construction techniques have achieved better engineering results under suitable conditions. However, influenced by the combination of the external environment and the complex mechanical characters of the backpacking of the wall, the lateral displacement of retaining wall has some problems, such as large construction work surface, high project cost, poor stability and so on.

\section{Engineering Situation}

The project of Jiang-Lian heavy industry east side slope protection and walkway cost 1,232,000 Yuan, and the construction period is 335 days. The project is located in the high-tech industrial park of Jinxian city. The project started in May, 2015, and it was used after the completion experience in July 2015. The surrounding environment protection requirements of the project are high, and the lateral displacement of the existing retaining wall should meet the requirement of safety and stability.

The construction technique about the reinforced concrete retaining wall's lateral displacement repairing is used to repair the lateral displacement of the retaining wall.

\section{Technical Principle}

In view of the factors of the construction quality of retaining wall's lateral displacement repairing, this paper puts forward a kind of construction technique for reinforced concrete retaining wall's lateral displacement repairing. The schematic diagram of the structure cross- 
section is shown in figure 1.

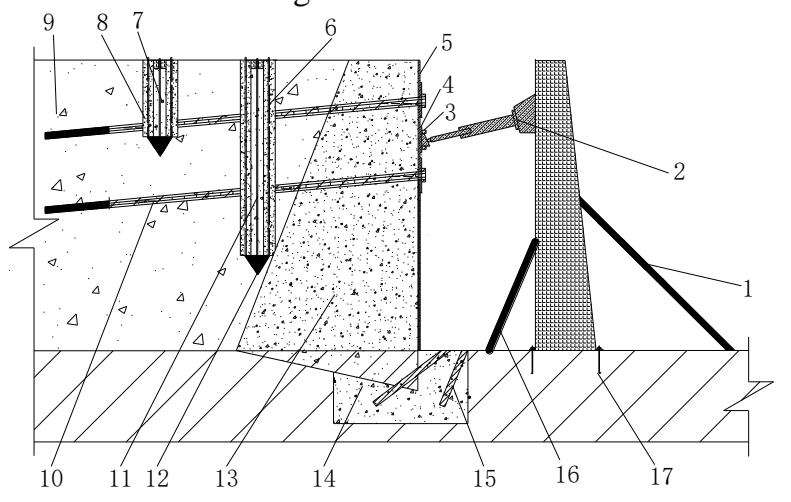

Figure 1 Schematic diagram of the structure cross-section

(Note: 1-Diagonal supporting steel column.2Jacking device.3-Pressure limit slot of retaining wall.4Transverse reaction steel plate. 5-Vertical reaction steel plate. 6- Double -layer pressure balance hose. 7Concrete filler. 8-Cement mortar curing area.9-The lateral soil of the wall. 10-Transverse tension reinforcement. 11- water filling pipe.12-Closed tube tip; 13- retaining wall; 14-Solidified reinforcing form. 15-Diagonal hole ; 16-Diagonal tension reinforcement; 17-Anchor bolt)

The principle of construction technology includes the following aspects:

1) Multi-azimuth synchronous loading

In the process of retaining wall displacement repairing, soften wall dorsal lateral soil through the secondary injection tube firstly, and gradually reduce the double-layer of pressure balance hose tube cavity of the water pressure to achieve the goal of the lateral soil pressure of the wall decreases. Meanwhile, tension force and top pressure are applied through lateral pull tabs and pressing device respectively to realize the simultaneous application of lateral load of retaining wall and reduce the requirements for loading device.

2) Effectively reducing of the wall pressure

2-5 rows of vertical holes are drilled in the lateral soil of the retaining wall, and the double-layer pressure balance hose is inserted synchronously. The lateral soil pressure was balanced by a water injection pipe in the inner tube, and the surrounding soil was softened by the secondary water injection to reduce the pressure of the wall in the construction process.

3) Evenly sharing of the wall load.

The vertical reaction steel plate and transverse reaction steel plate are arranged cross intersection on retaining wall surface, and the vertical counterforce plate is facing down while the transverse anti-force plate is facing up. The jacking is applied to the cross intersection of the vertical reaction steel plate and the transverse reaction steel plate, and the pressure load is diffused. Meanwhile, the vertical reaction steel plate is connected with the transverse tension reinforcement to expand the range of the anchorage force of transverse tension bars.

4) Solidifying and reinforcing of foundation soil

According to the situation of retaining wall foundation soil, drill holes and grout to form cement mortar solidifying area at the bottom of low bearing capacity retaining wall foundation after repairing the lateral displacement, which can effectively improve the lower soil capacity of retaining wall foundation.

\section{Construction Preparation}

\subsection{Material Preparation}

Before construction, according to the designed engineering quantity requirement and the site condition, the materials consumption of water, cement, steel plate, fine sand, gravel or medium coarse sand, tension reinforcement, double-layer pressure balance hose, pressure pulp pipe and so on is determine. And the performance index of the material should be tested.

\subsection{Work Preparation}

1) The main construction equipment should be organized in time, and its specifications and quantity should meet the requirements of the site construction. The equipment and instruments for measuring devices should be recognized by the metrological supervision unit above the city level.

2 ) According to the requirements of site construction, engineering surveying and mapping is carried out on the site to find out the compaction degree of the lateral soil property of the wall, groundwater level and lateral deformation of retaining wall. The layout of the double-layer pressure balance hose and the pressing device is marked on the spot.

3) The setting depth and soil pressure value of the double-layer pressure balance hose are determined by engineering calculation.

4) According to the construction requirements, the construction materials such as cement, sand, gravel and steel are prepared to meet the construction quality requirements.

5 ) To prepare detailed construction technology, construction parameters, quality control measures and emergency plan, analyze and study the quality control difficulties during the construction process, and put forward the concrete construction technology plan.

\section{Construction Process Analysis}

\subsection{Construction Technology Process}




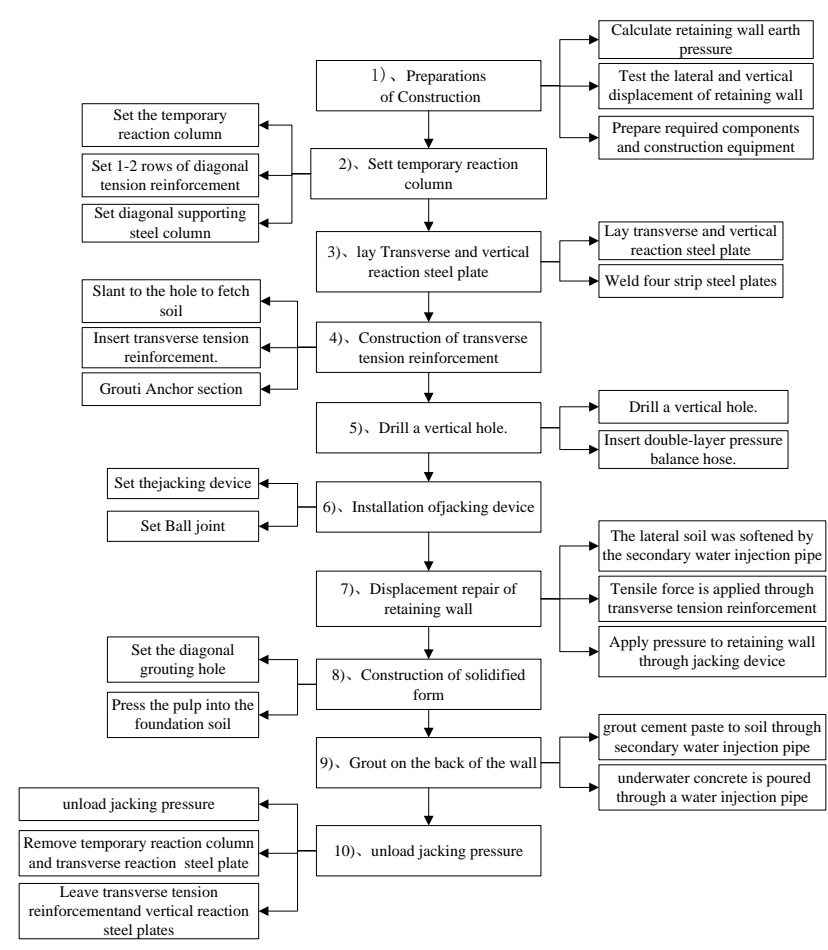

Figure 2 Construction process of construction technique about the reinforced concrete retaining wall's lateral displacement repairing

\subsection{Construction Quality Control Points and Quality Assurance Measures}

\subsubsection{The temporary reaction column setting}

(1) The temporary reaction column is hoisted to the construction site, and the pressure distribution plate is set up at the bottom of the temporary reaction column, so that the temporary reaction column is connected to the ground by the anchor bolt.

(2) According to the requirements of horizontal pressure, 1-2 rows of diagonal tension reinforcement are set vertically in temporary reaction cylinder to the side of retaining wall, and diagonal supporting steel column is set along the departure side of retaining wall. The diagonal supporting steel column and temporary reaction column are firmly connected by bolts after tensioning diagonal tension reinforcement.

\subsubsection{Transverse and vertical reaction steel plate laying}

(1) The punched holes of transverse tension reinforcement are preset on the vertical reaction steel plate, and the diameter of the hole is not less than the diameter of the anchor bar.

(2) Vertical anti-force steel plates and transverse reaction steel plates intersect each other on the wall surface of the retaining wall, and the vertical counterforce plate is facing down while the transverse anti-force plate is facing up.

(3) Four bar steel plates are welded on transverse reaction steel plate at the intersection of vertical and transverse counterforce plates to form the jacking limit slot of the retaining wall.

\subsubsection{Transverse tension reinforcement construction}

(1) Transverse movable scaffold or scaffold is set up, and take the soil through the punched holes of transverse tension reinforcement on retaining wall surface. The tensile force of the anchorage section shall meet the requirements of tension.

(2) After removing the debris in the hole, firstly, insert the transverse tension reinforcement, then the anchor section is grouted to form the anchorage section.

\subsubsection{Drill the vertical hole and balance the soil pressure}

(1) 2-5 rows of soil taking holes are drilled in the back of the retaining wall, and the depth of the closer hole is larger, but the maximum depth is no more than $3 / 4$ of the wall height.

(2) Insert the double-layer pressure balance hose immediately into the hole. The bottom of the doublelayer pressure balance hose is connected with the closed tube tip, and the inner tube cavity is not seepage while the outer tube wall cavity is provided with a water seepage hole.

(3) In the inner tube cavity, a water injection pipe is set up, and a secondary water injection pipe is set in the gap between the inner tube cavity and outer tube cavity.

(4) The pressure of water injection is equal to 0.9-1.1 times the active earth pressure value through a water injection pipe water flood into the inner tube cavity for balancing the lateral soil pressure (preventing collapse) into the inner tube.

\subsubsection{The jacking device installing}

(1) The jacking device is put between the temporary reaction column and the jacking limit slot of the retaining wall. The two ends of the jacking device are the front pressure support and the rear pressure support, and the center is the pressure jack.

(2) The front pressure support and rear pressure support are closely connected with the retaining wall's surface and the temporary reaction column.

(3) The force direction of the jacking device should be adjusted to make it downward, and the angle of the horizontal line is 5-15 degrees.

(4) The jacking device is arranged longitudinally along the retaining wall, with spacing between $5-10 \mathrm{~m}$, and the jacking device should be set separately on both sides of the retaining wall.

\subsubsection{Retaining wall's lateral displacement repairing}

(1) After the cement mortar of anchorage section of transverse tension reinforcement meet the require strength, soften the lateral soil pressure of the wall through the secondary injection tube, and simultaneously 
reduce the water pressure of the double-layer pressure balance hose.

(2) While softening the back soil of the wall, tension force and top pressure are applied through lateral pull tabs and pressing device respectively.

(3) The jacking device between the two deformation joints is applied simultaneously. The pressure rate of the jacking device is controlled at $0.5 \mathrm{kN} / \mathrm{s}$, and the rate of tension is controlled at $0.05 \mathrm{kN} / \mathrm{s}$.

(4) In the process of recovering retaining wall displacement, the displacement of the retaining wall was synchronously observed by the surveying and mapping equipment, and the jacking pressure was stopped when the different displacement of the deformation joints between the two sides of the jacking pressure section was less than $1 \mathrm{~cm}$.

\subsubsection{Solidified form construction}

(1) From the base of the retaining wall, the inclined downward sloping cement mortar hole is arranged along the retaining wall along the retaining wall. The depth of the diagonal grouting hole is not less than that of the retaining wall foundation.

(2) After the diagonal grouting hole is finished, push the cement mortar into foundation soil synchronously to form the solid reinforcing body.

(3) The grouting construction process of solidified reinforcing form is the following steps. sample determination of soil moisture content $\rightarrow$ testing the position of the grouting hole $\rightarrow$ diagonally opening hole (hole depth not less than $1 \mathrm{~m}$ ) $\rightarrow$ inserting grouting pipe $\rightarrow$ performing low pressure osmotic grouting $\rightarrow$ measuring saturation $\rightarrow$ inspection.

\subsubsection{Wall cavity grouting}

(1) After the solidified reinforcing body meet the required strength, pushing cement mortar into soil through the secondary water injection pipe, and the cement mortar solidification zone is formed outside the secondary water injection pipe' cavity

(2) The cement mortar is filled in the firstly water injection pipe cavity, and the concrete filling body is formed inside the firstly water injection pipe.

\subsubsection{Jacking pressure removing}

(1) After the concrete inside the inner tube cavity meet the required strength, the jacking pressure is removed, and the temporary reaction column and transverse reaction steel plate are removed, but the transverse tension bars and vertical anti-force steel plates are retained.

(2) Anti-corrosion treatment is applied for the transverse tension reinforcement and vertical reaction steel plates.

\section{Engineering Application Effect Analysis}

The construction technology can realize the retention of the retaining wall, reduce the material cost of the site construction, and reduce the cost of construction waste disposal and the amount of building materials. Meanwhile, the technology can optimize the system of retaining wall structure. It makes full use of the soil softening and taking soil to reduce the effects of wall back soil pressure, which can effectively improve the mechanical properties of retaining wall structure. The technology can not only save the cost of site construction, but also enhance the safety during construction. Through the analysis of life-cycle cost, it shows that the construction technology can save about $8 \%-10 \%$ of the project cost, and the economic benefit is significant.

In view of the application effect, according to the force characteristics of the retaining wall and the induced factors of lateral displacement, the lateral force is applied to the retaining wall from the external jacking pressure and internal tension of retaining wall. Through drilling holes to get soil and softening the soil, the soil pressure of wall back can be reduced when repairing the lateral displacement. Then the force characteristics of retaining wall structure can be improved and the requirement of construction load in the process of displacement repairing can be reduced, which can save the materials and equipment in the process of construction. In addition, the construction technology has a high working efficiency and small environmental pollution, which can effectively reduce the impact of construction on the environment.

\section{Conclusions}

Due to the influence of many uncertain factors, the retaining wall has a certain degree of lateral displacement during the process of using. Based on the force characteristics and lateral deformation of retaining wall, a kind of lateral displacement repairing technology of reinforced concrete retaining wall was proposed in this paper.

(1) In view of the stability of retaining wall lateral displacement repairing and the improvement of construction efficiency, a kind of lateral displacement repairing technology of reinforced concrete retaining wall was proposed. Meanwhile, the construction process and quality control points of the technology are systematically analyzed to demonstrate the rationality and engineering practical.

(2) Based on the need of the retaining wall lateral displacement repairing, the construction process and application effect of the technology were analyzed, and the research engineering application value of the technology was illustrated.

\section{Acknowledgment}

[Funding Project] The National Natural Science

Foundation of China (51409140); 


\section{References}

1. PAIK K H, SALGADO R. Estimation of active earth pressure against rigid retaining walls considering arching effect[J]. Geotechnique, 53(7): 643-653(2003).

2. FANG Y S, ISHIBASHI I. Static earth pressures with various wall movements[J]. Journal of Geotechnical Engineering, ASCE,112(3):317333(1986).

3. He Shan Guo. The discusses about the ways and measures of strengthening and reforming the disease and old retaining wall. [J]. Water Resources Planning and Design, 02:30-34(2013).

4. Zhou Jian. Model test and numerical simulation of retaining wall under different displacement modes[J]. Chinese Journal of Rock Mechanics and Engineering, 30(S2):3721-3727(2011).

5. Wei Xing Xing. Retaining Wall's Lateral Displacement Repairing Structure Design and Function Test Study [D].Nanchang: Nanchang Hangkong University(2017).

6. Sun Jia Wen. Study on strengthening mechanism and stability of highway terraced foundation retaining wall. [J]. Value Engineering, 37(04):117-118(2018).

7. Li Zhen. Reinforcing concrete buttress retaining wall. [J]. Modern Mining, 29(09):140+180(2013).

8. Sun Chang Li. An example analysis about reinforcement engineering of a river retaining wall. [J]. Guangdong Water Resources and Hydropower,5:30-34(2017).

9. Zhang Yan. Analysis and reinforcement measures for instability of a gravity retaining wall. [J]. Jiangsu Construction, 05:66-67(2015).

10. Gan Li Li. The application of geogrid construction technology to prevent the large displacement of retaining wall is too. [J]. Guangdong Building Materials,29(08):70-72(2013). 